\title{
CNTs/TiC Reinforced Titanium Matrix Nanocomposites via Powder Metallurgy and Its Microstructural and Mechanical Properties
}

\author{
Katsuyoshi Kondoh, ${ }^{1}$ Thotsaphon Threrujirapapong, ${ }^{1}$ Hisashi Imai, ${ }^{1}$ Junko Umeda, ${ }^{1}$ and Bunshi Fugetsu ${ }^{2}$ \\ ${ }^{1}$ Joining and Welding Research Institute, Osaka University, 11-1 Mihogaoka, Ibaragi, Osaka 567-0047, Japan \\ ${ }^{2}$ Section of Environmental Biology, Faculty of Environmental Earth Science, Hokkaido University, Sapporo, \\ Hokkaido 060-0810, Japan
}

Correspondence should be addressed to Katsuyoshi Kondoh, kondoh@jwri.osaka-u.ac.jp

Received 30 August 2008; Accepted 17 December 2008

Recommended by Doron Yadlovker

By using pure titanium powder coated with unbundled multiwall carbon nanotubes (MWCNTs) via wet process, powder metallurgy (P/M) titanium matrix composite (TMC) reinforced with the CNTs was prepared by spark plasma sintering (SPS) and subsequently hot extrusion process. The microstructure and mechanical properties of $\mathrm{P} / \mathrm{M}$ pure titanium and reinforced with CNTs were evaluated. The distribution of CNTs and in situ formed titanium carbide (TiC) compounds during sintering was investigated by optical and scanning electron microscopy (SEM) equipped with EDS analyzer. The mechanical properties of TMC were significantly improved by the additive of CNTs. For example, when employing the pure titanium composite powder coated with CNTs of 0.35 mass $\%$, the increase of tensile strength and yield stress of the extruded TMC was $157 \mathrm{MPa}$ and $169 \mathrm{MPa}$, respectively, compared to those of extruded titanium materials with no CNT additive. Fractured surfaces of tensile specimens were analyzed by SEM, and the uniform distribution of CNTs and TiC particles, being effective for the dispersion strengthening, at the surface of the TMC were obviously observed.

Copyright ( $\odot 2008$ Katsuyoshi Kondoh et al. This is an open access article distributed under the Creative Commons Attribution License, which permits unrestricted use, distribution, and reproduction in any medium, provided the original work is properly cited.

\section{INTRODUCTION}

Carbon nanotubes (CNTs), found in 1976s by Oberlin et al. [1], have a potential to be used as attractive reinforcements of the composite materials because they have a low density of $1.3 \mathrm{~g} / \mathrm{cm}^{3}$ and $973 \mathrm{GPa}$ Young's modulus [1-3]. It is also well known that CNT also has excellent electrical and thermal conductivities [4]. Previous studies indicated characteristics of the metal matrix composites (MMCs) reinforced with CNTs, where industrial metals such as aluminum, magnesium, nickel, copper, and their alloys were used [5-14]. Titanium (Ti) and titanium alloy are also interested as the matrix material because they are widely used in various industrial applications, for example, automotive, motorcycles, and airplane industries due to their high specific strength and Young's modulus. Their chemical and petrochemical applications are also excellent because of their high corrosion resistance [15]. On the other hand, when adding CNTs into metals as reinforcements, powder metallurgy $(\mathrm{P} / \mathrm{M})$ process is more suitable than ingot metallurgy (I/M) because the separation of CNTs from the molten metals easily occurs due to their buoyancy caused by the low density. Furthermore, the agglomeration of the bundled CNTs always exists in $\mathrm{P} / \mathrm{M}$ composite materials because of their van der Waals force, which is attractive or repulsive between carbon atoms $[16,17]$. One of the researchers in the previous study showed an effective preparation of unbundled CNTs by using the zwitterionic surfactant solutions via wet process [18]. In this study, the microstructures and mechanical properties of $\mathrm{P} / \mathrm{M}$ titanium matrix composite (TMC) reinforced with unbundled CNTs by using the above wet process. It is strongly expected that the combination of Ti and CNTs will serve superior tensile strength to the conventional TMC. The strengthening mechanism of the composites with CNTs is discussed by their microstructures analysis and identification of the dispersoids. 


\section{EXPERIMENTAL}

Atomized pure Ti powders, having a mean particle size of $30 \mu \mathrm{m}$, were used as starting materials. The impurity contents of raw powder were Fe: 0.03, Si: 0.01, Mg: <0.001, Cl: $<0.002$, O: $0.21, \mathrm{~N}: 0.02, \mathrm{C}:<0.01$ (mass\%). The zwitterionic surfactant solution with CNT concentration of 3.0 mass $\%$ was prepared. Multiwall CNTs with about $10 \mathrm{~nm}$ diameter and $0.5 \sim 1 \mu \mathrm{m}$ length were employed in this experiment. Polar zwitterions generally had a high solubility in water, but a poor solubility in most organic solvents. 3-(N, Ndimethylstearylammonio) propanesulfonate, a typical linear zwitterionic surfactant, was used in this study. It had both hydrophobic and hydrophilic groups. Electrostatic interactions, having larger attractive forces than the van der Waals forces between CNTs, occurred at the hydrophilic because of the positive charge and negative charges on their headgroups. Therefore, the unbundled CNTs existed in the zwitterionic surfactant solution [18]. Ti powders were dipped into the solution, and subsequently dried in oven at $373 \mathrm{~K}$ for 10.8 kiloseconds. The composite $\mathrm{Ti}$ powders coated with CNTs were obtained, and the individually independent CNT were observed on the powder surface as shown in Figure 1. Surfactant solids also existed, and should be removed before hot consolidation because they changed to gases at elevated temperature over $773 \mathrm{~K}$ [19], and would cause the pores as material defects. From a viewpoint of the thermal resolution of the surfactant solids, the $\mathrm{Ti}$ composite powders with CNTs were consolidated by spark plasma sintering (SPS, Syntech Co. SPS-1030S) process with two steps heating; $873 \mathrm{~K}$ for 3.6 kiloseconds for their removal, and $1073 \mathrm{~K}$ for 1.8 kiloseconds for the vacuum sintering. The applied load during the heating was $20 \mathrm{kN}$ and $41.6 \mathrm{kN}$, respectively. The sintered $\mathrm{Ti}$ composite compact was heated at $1073 \mathrm{~K}$ for 180 seconds in argon atmosphere, and immediately served to hot extrusion. The extrusion ratio, speed, and die temperature were $37,3.0 \mathrm{~mm} / \mathrm{s}$ and $673 \mathrm{~K}$, respectively. The preheating at $273 \mathrm{~K}$ was enough for in situ synthesis of titanium carbides (TiCs) by the reaction of $\mathrm{Ti}$ matrix and CNTs. Microstructure and phase characterizations were investigated by X-ray diffraction (XRD, Shimadzu XRD6100), optical microscope and scanning electron microscope with energy dispersive spectrometry (SEM-EDS, JOEL, JSM6500F). P/M extruded TMC materials were machined to tensile specimen bars with $3.5 \mathrm{~mm}$ diameter and $10 \mathrm{~mm}$ gauge length, and evaluated at room temperature. The fractured surface of the specimens was observed by FE-SEM to investigate the dispersion strengthening mechanism by CNTs and in situ TiCs.

\section{RESULTS AND DISCUSSION}

Chemical analysis on $\mathrm{P} / \mathrm{M}$ extruded $\mathrm{Ti}$ material and reinforced with unbundled CNTs indicates that the carbon content is $<0.01 \%$ and $0.351 \%$, respectively. It means the content of dispersed CNTs of the TMC material is about $0.35 \%$. The oxygen content is $0.21 \%$ and $0.27 \%$, respectively. That is, the oxidation with $600 \mathrm{ppm}$ during the consolidation of the composite $\mathrm{Ti}$ powders by the process as mentioned

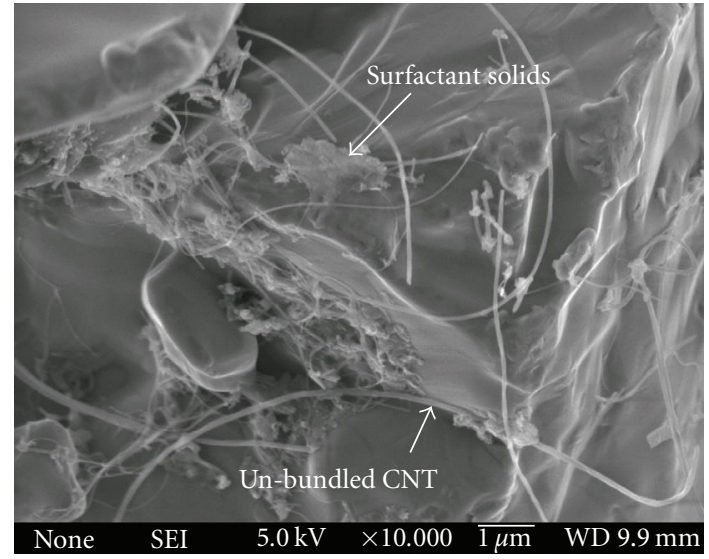

FIGURE 1: SEM observation on surface of pure titanium powder coated with unbundled CNTs.

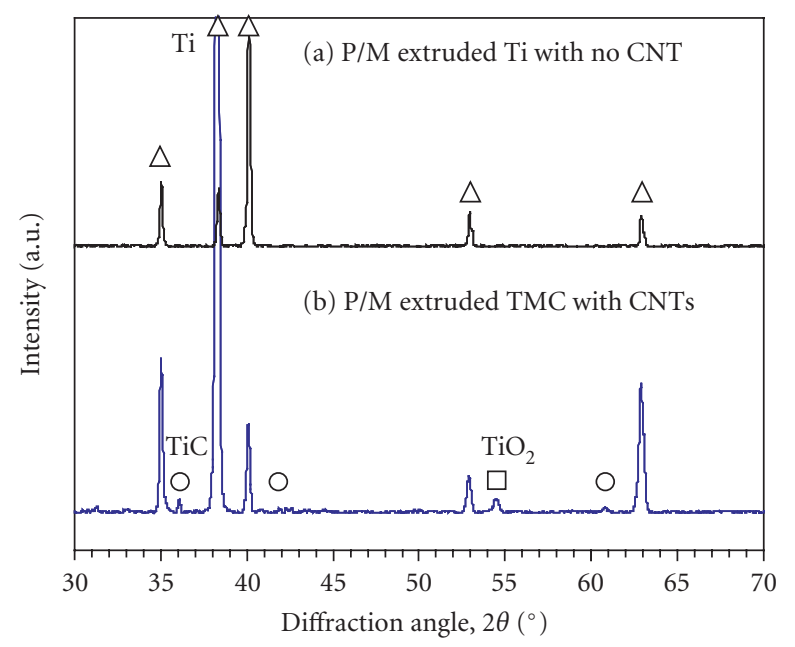

FIgURE 2: XRD patterns of (a) P/M extruded titanium and (b) reinforced with CNTs.

above slightly occurred. XRD patterns shown in Figure 2 obviously show the peaks of in situ synthesized TiCs of the composite material at $2 \theta=36.08^{\circ}, 41.74^{\circ}$, and $60.89^{\circ}$. Additionally, there is no difference of $2 \theta$ for titanium peaks between extruded $\mathrm{Ti}$ and reinforced with CNTs. A mean grain size of the TMC with CNTs and no CNT is around $6 \mu \mathrm{m}$ and $5 \mu \mathrm{m}$, respectively, and no significant difference between them is observed. The optical and scanning electron microscope observation results on extruded TMC with CNTs are shown in Figure 3. TiC particles are uniformly distributed in the matrix, that is, the original distribution of unbundled CNTs on Ti powder surface is homogeneous. The image analysis on the optical microstructure of Figure 3(a) indicates a mean particle size of in situ formed $\mathrm{TiC}$ is $1.8 \mu \mathrm{m}$. The TiC dispersoids have two different shapes: elongated and spherical type. Most of the formers, having a length of about $10 \mu \mathrm{m}$ or less, are lined along the extrusion direction because of the severe plastic deformation of the titanium matrix powder and recombination of CNTs during hot extrusion. Then, CNTs are also lined along the direction, 


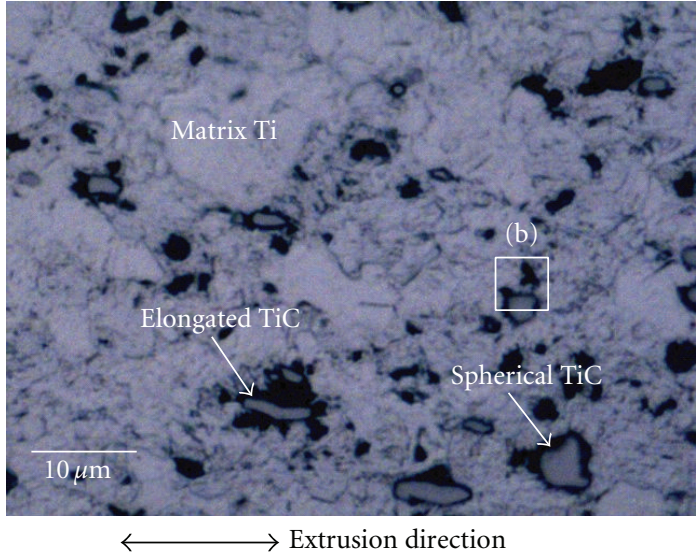

(a)

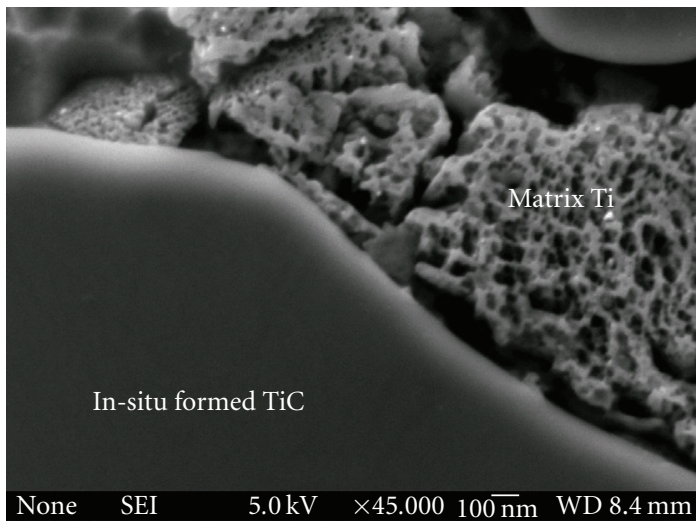

(b)

Figure 3: Optical microstructure of (a) P/M extruded TMC with CNTs and (b) interface observation between $\mathrm{TiC}$ and titanium matrix by SEM.

TABle 1: Tensile properties of $\mathrm{P} / \mathrm{M}$ extruded titanium and reinforced with CNTs.

\begin{tabular}{lccc}
\hline & UTS/MPa & YS/MPa & Elongation (\%) \\
\hline P/M extruded titanium & 585 & 423 & 29.7 \\
P/M extruded TMC with CNTs & 742 & 592 & 26.0 \\
\hline
\end{tabular}

and reacted with the titanium matrix, resulting elongated TiCs. The formation of spherical TiC particles indicates the incompletely disassembled CNTs, causing the coarse TiC particles, partially exist on the powder surface even after this wet process. The dark areas around any $\mathrm{TiC}$ particle are detected, and the magnified observation by FE-SEM is shown in Figure 3(b). It is obviously clarified that they correspond to the titanium matrix, and have a good bonding with the TiC particle due to the solid-state reaction in heating at $1273 \mathrm{~K}$. Furthermore, the titanium matrix seems as the porous lamellar structure in perpendicular direction with paper, which is presumed corroded by hydrous solution during etching. This trend may be due to the effect of $\mathrm{TiC}$ particle on the orientation of lamellar structure at interfaces during phase transformation in hot extrusion process.

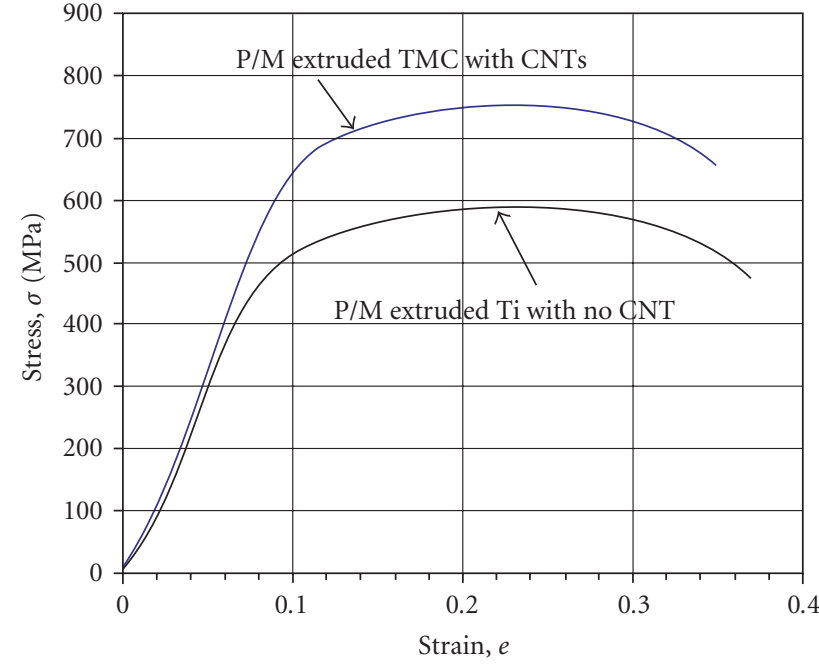

Figure 4: Stress-strain curves of $\mathrm{P} / \mathrm{M}$ extruded titanium and reinforced with CNTs.

The tensile test results are shown in Figure 4. The ultimate tensile strength, yield stress and elongation of them are summarized in Table 1. Tensile properties of $\mathrm{P} / \mathrm{M}$ extruded $\mathrm{Ti}$ with no CNT prepared in this study are almost same as those of the conventional wrought titanium [20]. Comparing the stress-strain curves of the wrought titanium materials, the increased UTS and YS are $157 \mathrm{MPa}$ and $169 \mathrm{MPa}$, respectively. When considering a very small increase of oxygen with $600 \mathrm{ppm}$, these mechanical improvements are due to the dispersion strengthening effect by unbundled CNTs and in situ synthesized TiC particles. As a remarkably suggested point, in spite of the above increase, the TMC composite reveals a large elongation of $26 \%$. This is because the total carbon content of 0.35 mass $\%$ is very small, compared to the conventional MMCs, and significantly effective for strengthening. Furthermore, when adding CNTs to $\mathrm{Ti}$ powder, the microvickers hardness values (HV0.05) increase from 261 to 285. Fractured surface observation of TMC specimen is shown in Figure 5. CNTs have been remained in matrix, and also confirmed by EDS analysis. CNTs with the original size and shape are observed at the surface of the composite. On the other hand, TiC particles formed by the reaction of CNT with Ti are also obviously observed. It means that solid-state sintering condition at $1073 \mathrm{~K}$ by SPS and preheating at $1273 \mathrm{~K}$ before extrusion are suitable to prepare the Ti composite including both of CNTs and $\mathrm{TiC}$ particles. The remained CNTs presumably improve the mechanical properties of TMC.

\section{CONCLUSIONS}

(1) Wet process using the zwitterionic surfactant solutions was effective to coat unbundled CNTs on Ti powder surface, and assemble them in P/M extruded titanium composite. (2) In situ formed $\mathrm{TiC}$ particles were also uniformly distributed in the matrix, and had elongated and spherical shapes. (3) Mechanical properties of tensile strength and microvicker's 


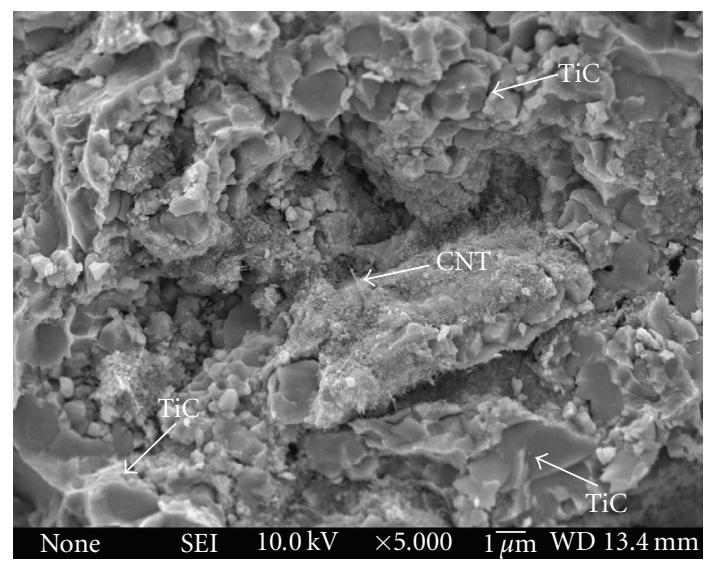

(a)

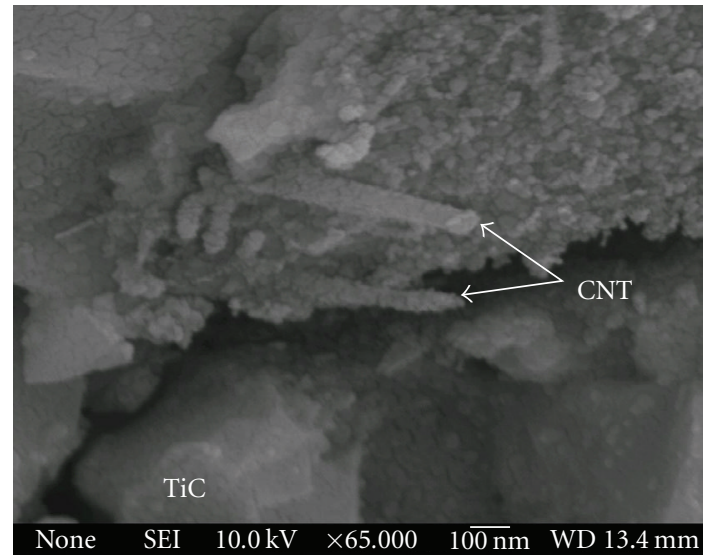

(b)

FIGURE 5: SEM observation on fractured surface of tensile specimen of TMC with CNTs.

hardness were remarkably improved by the reinforcement of 0.35 mass $\%$ CNTs. In particular, TMC via this process showed a good balance of high UTS of $742 \mathrm{MPa}$ and large elongation of $26 \%$ when using pure titanium powder as input raw materials. (4) Observation on the fractured surface of tensile specimens indicated that CNTs were still remained with no morphological change and promoted their mechanical properties.

\section{REFERENCES}

[1] A. Oberlin, M. Endo, and T. Koyama, "Filamentous growth of carbon through benzene decomposition," Journal of Crystal Growth, vol. 32, no. 3, pp. 335-349, 1976.

[2] S. Iijima, C. Brabec, A. Maiti, and J. Bernholc, "Structural flexibility of carbon nanotubes," Journal of Chemical Physics, vol. 104, no. 5, pp. 2089-2092, 1996.

[3] M. R. Falvo, G. J. Clary, R. M. Taylor II, et al., "Bending and buckling of carbon nanotubes under large strain," Nature, vol. 389, no. 6651, pp. 582-584, 1997.

[4] M. S. Dresselhaus, G. Dresselhaus, and Ph. Avouris, Carbon Nanotubes, Springer, Berlin, Germany, 2001.

[5] R. George, K. T. Kashyap, R. Rahul, and S. Yamdagni, "Strengthening in carbon nanotube/aluminium (CNT/Al) composites," Scripta Materialia, vol. 53, no. 10, pp. 1159-1163, 2005.

[6] T. Kuzumaki, T. Hayashi, K. Miyazawa, H. Ichinose, K. Ito, and Y. Ishida, "Processing of ductile carbon nanotube/C60 composite," Materials Transactions, vol. 39, no. 5, pp. 574-577, 1998.

[7] C. L. Xu, B. Q. Wei, R. Z. Ma, J. Liang, X. K. Ma, and D. H. $\mathrm{Wu}$, "Fabrication of aluminum-carbon nanotube composites and their electrical properties," Carbon, vol. 37, no. 5, pp. 855858, 1999.

[8] K. T. Kim, J. Eckert, S. B. Menzel, T. Gemming, and S. H. Hong, "Grain refinement assisted strengthening of carbon nanotube reinforced copper matrix nanocomposites," Applied Physics Letters, vol. 92, no. 12, Article ID 121901, 3 pages, 2008.

[9] K. T. Kim, S. I. Cha, S. H. Hong, and S. H. Hong, "Microstructures and tensile behavior of carbon nanotube reinforced Cu matrix nanocomposites," Materials Science and Engineering A, vol. 430, no. 1-2, pp. 27-33, 2006.
[10] J. Yang and R. Schaller, "Mechanical spectroscopy of $\mathrm{Mg}$ reinforced with $\mathrm{Al}_{2} \mathrm{O}_{3}$ short fibers and C nanotubes," Materials Science and Engineering A, vol. 370, no. 1-2, pp. 512-515, 2004.

[11] E. Carreño-Morelli, J. Yang, E. Couteau, et al., "Carbon nanotube/magnesium composites," Physica Status Solidi (A), vol. 201, no. 8, pp. R53-R55, 2004.

[12] C. S. Goh, J. Wei, L. C. Lee, and M. Gupta, "Simultaneous enhancement in strength and ductility by reinforcing magnesium with carbon nanotubes," Materials Science and Engineering A, vol. 423, no. 1-2, pp. 153-156, 2006.

[13] C. S. Goh, J. Wei, L. C. Lee, and M. Gupta, "Development of novel carbon nanotube reinforced magnesium nanocomposites using the powder metallurgy technique," Nanotechnology, vol. 17, no. 1, pp. 7-12, 2006.

[14] Y. Shimizu, S. Miki, T. Soga, et al., "Multi-walled carbon nanotube-reinforced magnesium alloy composites," Scripta Materialia, vol. 58, no. 4, pp. 267-270, 2008.

[15] C. Leyens and M. Peters, Titanium and Titanium Alloys, WILEY-VCH, Weinheim, Germany, 1st edition, 2003.

[16] T. Hertel, R. E. Walkup, and P. Avouris, "Deformation of carbon nanotubes by surface van der Waals forces," Physical Review B, vol. 58, no. 20, pp. 13870-13873, 1998.

[17] L. Y. Jiang, Y. Huang, H. Jiang, et al., "A cohesive law for carbon nanotube/polymer interfaces based on the van der Waals force," Journal of the Mechanics and Physics of Solids, vol. 54, no. 11, pp. 2436-2452, 2006.

[18] B. Fugetsu, W. Han, N. Endo, Y. Kamiya, and T. Okuhara, "Disassembling single-walled carbon nanotube bundles by dipole/dipole electrostatic interactions," Chemistry Letters, vol. 34, no. 9, pp. 1218-1219, 2005.

[19] K. Kondoh, H. Fukuda, H. Imai, and B. Fugetsu, "Microstructures and mechanical properties of magnesium composite alloys dispersed with carbon nanotube via powder metallurgy process," in Proceedings of the TMS Annual Meeting on Magnesium Technology, pp. 289-291, New Orleans, La, USA, March 2008.

[20] C. Ouchi, H. Iizumi, and S. Mitao, "Effects of ultra-high purification and addition of interstitial elements on properties of pure titanium and titanium alloy," Materials Science and Engineering A, vol. 243, no. 1-2, pp. 186-195, 1998. 

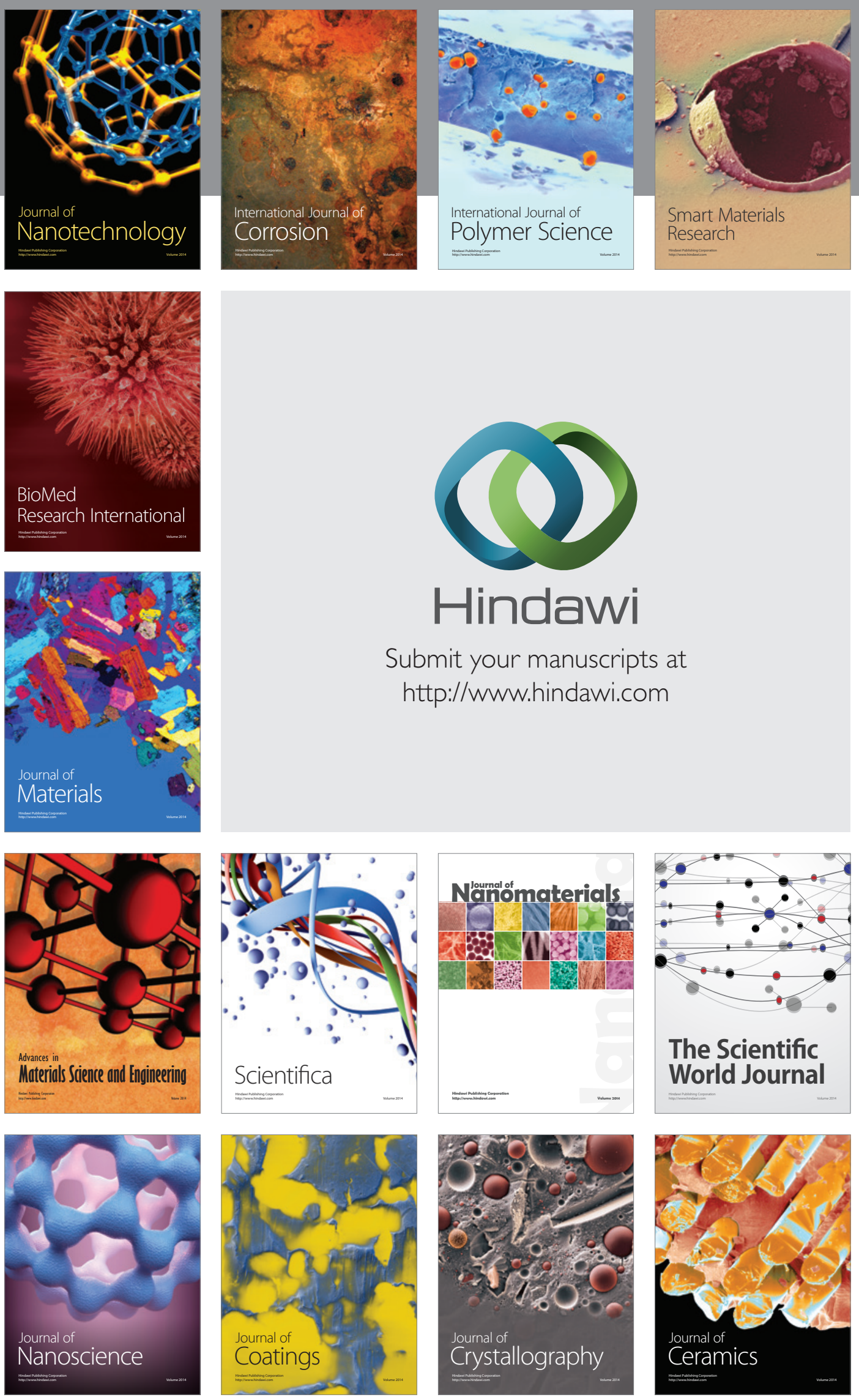

The Scientific World Journal

Submit your manuscripts at

http://www.hindawi.com

\section{World Journal}

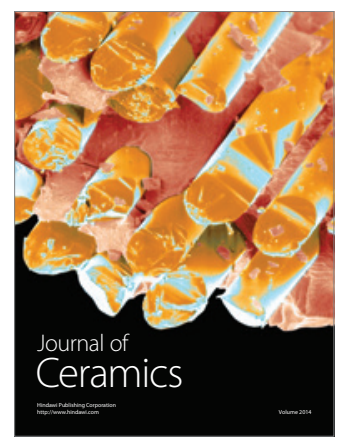

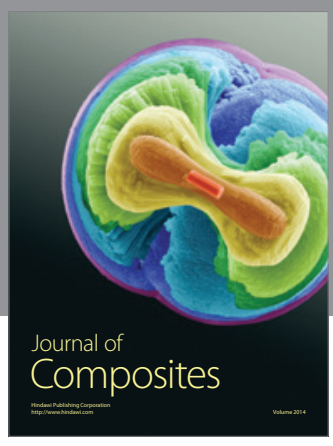
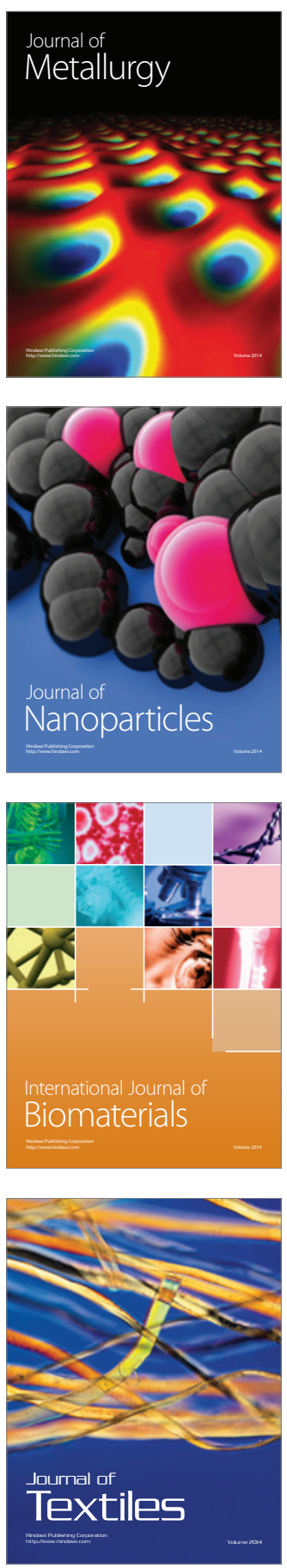